\title{
The Effect of TDZ and 2, 4-D Concentrations on the Induction of Somatic Embryo and Embryogenesis in Different Cocoa Genotypes
}

\author{
A. K. Quainoo (Corresponding author) \\ Department of Biotechnology, Faculty of Agriculture \\ University for Development Studies, Tamale, Ghana \\ E-mail: aquainoo@googlemail.com
}

B. I. Dwomo

Department of Agronomy, Faculty of Agriculture

University for Development Studies, Tamale, Ghana

Received: December 27, 2011

Accepted: January 21, 2012 Published: March 1, 2012

doi:10.5539/jps.v1n1p72

URL: http://dx.doi.org/10.5539/jps.v1n1p72

\begin{abstract}
The effect of 2, 4-D and TDZ concentrations on primary embryogenesis seem to be genotype dependent. There were significant differences between the control and the other treatments on somatic embryo production by genotype AMAZ 3-2. Genotype COCA 3370-5 did not show any significant difference among the treatments

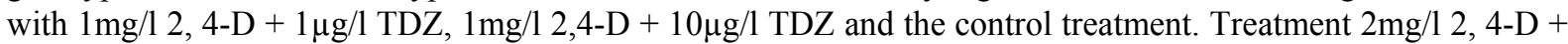
$10 \mu \mathrm{g} / 1 \mathrm{TDZ}$ seem to be better for the production of somatic embryos by genotype COCA 3370-5. Lower concentrations of 2, 4-D + TDZ seem to generate greater proportions of normal somatic embryos as compared with higher 2,4-D + TDZ by genotypes AMAZ 3-2 and COCA3370-5

Somatic embryogenesis using floral tissue explants was used to induce primary somatic embryos from the staminodes of 16 cocoa genotypes. Four genotypes (AMAZ 3-2, AMAZ 10-1, COCA 3370-5 and GU 183H) showed high frequencies of embryogenesis while the remaining genotypes generated little or no embryos. Secondary embryos were induced from the cotyledonary explants of the four genotypes that exhibited efficient primary embryogenesis. Percentage embryogenesis generally increased with culture time. GU 183 which demonstrated the highest primary and secondary embryogenesis recorded the lowest conversion rate of somatic embryo into plantlets.
\end{abstract}

Keywords: Thidiazuron, Dichlorophenoxyacetic acid, Cocoa, Somatic embryos, Embryogenesis, Genotye

\section{Introduction}

Numerous efforts has been made to improve the quality and security of conservation offered by field gene banks and to understand and overcome seed recalcitrance to make seed storage more widely available. Tissue culture techniques are of great interest for collecting, multiplication and storage of plant germplasm (Engelmann, 1997). These techniques allow the propagation of plant materials with high multiplication rates in an aseptic environment. The procedure through meristem culture and somatic embryogenesis also ensures the production of disease free stock materials making quarantine procedures for international exchange of germplasm easy.

Currently cocoa trees are mainly propagated by seeds. Plant regenerated through somatic embryogenesis provides an alternative approach for clonal propagation of cocoa. However, the conversion rates of somatic embryos into plantlets are still low (Fang et al., 2004; Quainoo, 2006; Quainoo, 2008). Li et al. (1998) reported the production of primary somatic embryos from floral explants at high frequency using thidiazuron (TDZ) and dichlorophenoxy acetic acid (2, 4-D). TDZ was registered in 1976 by Schering AG (Berlin Germany) as a cotton defoliate (Arnadt et al., 1979). TDZ was reported to show high activity in promoting growth of cytokinin depended callus cultures of Phaseolus lunatus (Mok et al., 1982). The research seek to study the effect of TDZ and 2,4-D concentrations on the induction of somatic embryo and embryogenesis in different cocoa genotypes with the long term objective of improving the conversion of cocoa somatic embryos into plantlets. 


\section{Materials and Methods}

\subsection{Induction of primary somatic embryos}

The protocol of Li et al., (1998) for the induction of cocoa somatic embryos was the basic procedure used. 16 cocoa genotypes (AMAZ 3-2, AMAZ 10-1, COCA 3370-5, EQX 0, EQX 69, GU 183 H, GU 239 H, IMC 20, MAN 15-5, MO 20, P 10, PA 88, PUCALA 1, RB 33-3, SIC 5 and SPA 9) were used for the experiment. These genotypes were collected at the University of Reading Cocoa Intermediate Quarantine Unit, UK. The process involved the induction of primary somatic embryos from the floral tissues of cocoa and the conversion of somatic embryos into plantlets. The genotypes used were evaluated for percentage embryogenesis and embryos per staminode over seven month period.

\subsection{Induction of secondary somatic embryos}

Four genotypes (AMAZ 3-2, AMAZ 10-1, COCA 3370-5 and GU $183 \mathrm{H}$ ) that showed satisfactory production of primary somatic embryos and were flowering at the time were selected for secondary embryogenesis. The secondary embryos were induced following the protocol of Maximova et al. (2001) where sections of cotyledons of approximately $4 \times 4 \mathrm{~mm}$ were cultured on secondary callus growth medium and then transferred onto auxin free embryo development medium for embryo production. The genotypes used were evaluated for percentage embryogenesis and average number of secondary embryos per cotyledonary material on embryo development medium over eight month period.

\subsection{Effect of TDZ and 2,4-D concentration on the induction of somatic embryos}

AMAZ 3-2 and COCA 3370-5 which exhibited high primary and secondary embryogenic frequencies and flowering were selected as experimental materials. The genotypes were assessed for callus formation, embryogenic frequency, type of embryo formation and the conversion of somatic embryos into plantlets. The protocol of Li et al. (1998) was used to induce primary callus growth and served as the control with 2,4-D and TDZ concentrations varied for the other treatment. Each treatment was replicated three times and the experiment repeated three times.

All the other stages of the protocol were maintained as described by Li et al., (1998) for primary embryogenesis and Maximova et al. (2002) for secondary embryogenesis.

\section{Results}

\subsection{Induction of primary and secondary somatic embryos}

Out of the 16 genotypes subjected to primary embryogenesis, four genotypes AMAZ 3-2, AMAZ 10-1, COCA 2270-5 and GU $183 \mathrm{H}$ showed high signs of embryogenesis and by week 12 had produced greater than $10 \%$ embryos per explants. The other genotypes generated little or no embryos. Figure 1 represents the percentage primary embryogenesis of the 16 genotypes used in experiment.

Broadly two categories of average number of primary somatic embryos per staminode were demonstrated by the genotypes. Genotypes that showed high signs of embryogenesis also demonstrated distinct peaks of production between one to six embryos per staminode over the culture period (AMAZ 3-2, AMAZ 10-1, COCA 2270-5 and GU $183 \mathrm{H}$ ). Genotypes that showed little embryonic potential generated embryos relatively uniformly of less than one embryo per staminode over the culture period (Figure 2).

Figure 3 ( $a$ and $b$ ) represent the embryogenic pattern of the four genotypes that showed high signs of embryogenesis and were selected for secondary embryogenesis. Experiments (a) and (b) were initiated two weeks apart with embryo production starting at 20 and 22 weeks after primary embryogenesis respectively. Percentage embryogenesis generally increased with culture time and reached its maximum between 24 to 30 weeks for AMAZ 3-2, AMAZ 10-1 and COCA 2270-5, and 30 to 34 weeks for GU $183 \mathrm{H}$.

\subsection{Conversion of somatic embryos into plantlets}

Table 2 represents percentages of embryos generated from different genotypes converted into plantlets.

\section{Discussion}

The protocol of Li et al. (1998) for the induction of somatic embryos permitted the identification of cocoa genotypes that undergo high frequency of embryogenesis. 16 cocoa genotypes were used out of which four genotypes (AMAZ 3-2, AMAZ 10-1, COCA 2270-5 and GU $183 \mathrm{H}$ ) demonstrated signs of high embryogenesis (20-50\%) (Figure1). These genotypes were selected for the induction of secondary embryogenesis with the remaining genotypes demonstrating little or no embryogenesis. Out of 19 cocoa genotypes Li et al. (1998) reported on 15 showed varying degree of embryogenesis ranging from 5\% to $100 \%$ (SCA 6-1). Generally 
embryo production started six weeks on embryo development medium for most genotypes. Percentage embryogenesis generally increased with culture time and reached its maximum between 16 and 20 weeks for genotypes demonstrating signs of high embryogenesis. The other genotypes generating few embryos either maintained a uniform frequency of embryogenesis or decreasing embryogenesis with culture time. The differences in embryogenesis may be attributed to the genotypes used, the occasion (since the experiments were repeated two weeks apart), physiological status of the donor plats and culture time. These conform to the observation of Li et al., (1998) and Maximova et al., (2002).

Two types of average number of primary embryos per staminode were demonstrated by the genotypes. Genotypes that showed high sighs of embryogenesis demonstrated a distinct peak of embryo production (AMAZ 3-2, AMAZ 10-1, COCA 2270-5 and GU $183 \mathrm{H}$ ) while genotypes that showed little embryogenic potential generated embryos relatively uniformly with time (figure 2). Generally, for all the genotypes, the peak of primary embryo production per staminode ranged between 10 and 24 weeks. These conform to the observation of Fang (2004) when she subjected various cocoa genotypes to somatic embryogenesis

Secondary somatic embryogenesis is a phenomenon whereby new somatic embryos are initiated from primary somatic embryos. As an experimental system, secondary somatic embryos have certain advantages over primary somatic embryogenesis. Secondary somatic embryogenesis has higher multiplication rate, synchronized embryo production and the system can be maintained for prolong period by repeated cycles of secondary embryogenesis (Raemakers et al., 1995).

The term conversion refers to the production of plantlets with functional roots and shoots systems. The ability of somatic embryos to convert into complete plantlets is depended upon the quality of the somatic embryos generated which is influenced by the conditions during each stage of embryogenesis (Raemakers et al., 1995). In the present work, genotype COCA 3370-5 recorded the highest embryo conversion rate of $57.14 \%$ and $40.91 \%$ for primary and secondary embryogenesis respectively. Genotype GU $183 \mathrm{H}$ which generated the highest number of embryos however, recorded the lowest embryo conversion rate of $16.67 \%$ and $5.13 \%$ for primary and secondary embryogenesis respectively (Table 2 ). The results indicated that though secondary embryogenesis is more prolific in somatic embryo generation primary embryogeneis is more effective in converting somatic embryos into plantlets. This finding is contrary to Fangs finding where secondary somatic embryos were more effective in converting into plantlets than primary somatic embryos (Fang, 2004; Quainoo, 2006).

The ability for embryos to convert into plantlets is depended on several factors such as embryo maturation, the synthesis and accumulation of storage compounds and the development of desiccation tolerance (Blackman et al., 1992; Xu et al., 1990). Storage compounds are important markers of physiological quality of somatic embryos and the failure to produce these may affect their final developmental stages and conversion into plantlets (Catarina et al., 2003; Cailloux et al., 1996).

The effect of 2,4-D and TDZ concentrations on primary embryogenesis seem to be genotype dependent. There was significant differences between the control $(2 \mathrm{mg} / 12$, 4-D $+5 \mu \mathrm{g} / \mathrm{l} \mathrm{TDZ})$ and the other treatments on somatic embryo production by genotype AMAZ 3-2. This suggested that the use of 2,4-D and TDZ concentrations below and above the control concentration as described by Li et al., (1998) and Maximova et al., (2002) did influence somatic embryo production by genotype AMAZ 3-2 (Table 3). Genotype COCA 3370-5 did not show any

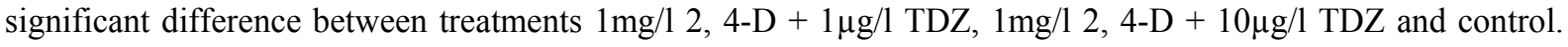
However, treatment $2 \mathrm{mg} / 12$, $4-\mathrm{D}+10 \mu \mathrm{g} / \mathrm{l} \mathrm{TDZ}$ seem to be better for the production of somatic embryos by genotype COCA 3370-5 (Table 3). Furthermore, lower concentrations of 2, 4-D + TDZ generated greater proportions of normal somatic embryos as compared with higher 2, 4-D + TDZ by genotypes AMAZ 3-2 and COCA3370-5 (Table 4). This may be attributed to the fact that 2, 4-D and cytokinins increase abnormal somatic embryo development in some plants such as Aralia cordata (Lee \& Soh, 1994). According to (Shoemaker et al., 1991) frequency and quality of embryogeneic response in soybeans embryos decreased with increase in 2, 4-D concentration which seem to support this findings. The effect of TDZ on the generation of somatic embryos of cocoa is further supported by the findings of Rehab and his associate (2011) that the production, maturation and growth of somatic embryos of date palm (Phoenix dactyliffera L.) resulted at low concentration of TDZ at $1 \mathrm{mg} / 1$. Figure 4 represent somatic embryos derived from the staminode of cocoa under going callus formation and at different stages of embryogenesis.

\section{Conclusion}

The induction, frequency, quality and the conversion of somatic embryos of cocoa into plantlets seem to genotype dependent. The response of TDZ and 2, 4-D on embryogenesis of cocoa also seem to be genotype 
dependent. Generally, lower concentrations of TDZ and 2,4-D seem appropriate for the generation, growth and development of somatic embryos of cocoa.

\section{Acknowledgements}

This work was supported by a scholarship from the Ghana government. A. K. Quainoo is grateful to Dr A. C. Wetten for his friendship and supervision of his Ph.D research and Professor Paul Hadley for the use of facilities at the University of Reading Cocoa Intermediate Quarantine Unit.

\section{References}

Blackman, S. A., Obendorf, R. K., \& Leopold, A. C. (1992). Maturation proteins and sugars in desiccation tolerance of developing soybean seeds. Plant Physiology, 100, 225-230. http://dx.doi.org/10.1104/pp.100.1.225

Cailloux, F., Julien-Guerrier, J., Linossier, I., \& Coudret, A. (1996). Long term embryo genesis and maturation of somatic embryos in Hevea brasiliensis. Plant Science, 120, 185-196. http://dx.doi.org/10.1016/S0168-9452(96)04491-3

Catarina, C. S., Randi, A. M., \& Viana, A. M. (2003). Growth and accumulation of storage reserves by somatic embryos of Ocotea catharinesis Mez. (Lauraceae). Plant Cell, Tissue and Organ Culture, 74, 67-71. http://dx.doi.org/10.1023/A:1023316907201

Engelmann, F. (1997). In vitro conservation methods. In: Biotechnology and Plant Genetic Resources: Conservation and Uses. (Eds, Callow, J. A., Ford-Llyoyd, B. V. and Newbury, J. H.) CAB International, Wallingford, pp. 119-161.

Fang, J. Y. (2004). (PhD Thesis) Cryopreservation of somatic embryos for long term germplasm conservation of cocoa (Theobroma cacaco L.). School of Plant Sciences, University of Reading, UK: 215.

Fang, J. Y.. Wetten, A., \& Hadley, P. (2004). Cryopreservation of cocoa (Theobroma cacaco L.). somatic embryos for long term germplasm storage. Plant Science, 166, 669-675. http://dx.doi.org/10.1016/j.plantsci.2003.11.002

Griga, M., (1993). Some factors affecting somatic embryogenesis effieciency in soybean (Glycine max (L.) Merr). Biologia Plantarum, 35(2), 179-189. http://dx.doi.org/10.1007/BF02925936

Lee, K. S., \& Soh, W. Y. (1994). Effect of abscisic acid on the number of somatic embryo cotyledons in tissue cultures of Aralia cordata Thunb. Korean Journal of Plant Tissue Culture, 21, 287-291.

Li, Z., Traore, A., Maximova, S., \& Guiltinan, M. (1998). Somatic embryogenesis and plant regeneration from floral explants of cacao (Theobroma cacao L.) using thidiazuron. In vitro Cellulara and Developmental Biology-Plants, 34, 293-299.

Maximova, S. N., Alemanno, L., Young, A., Feffiere, N., Traore, A., \& Guiltinan, M. J. (2002). Efficiency, genotypic variability, and cellular origin of primary and secondary somatic embryogenesis of Theobroma cacao L. In vitro Cellular and Developmental Biology-Plant, 38, 252-259. http://dx.doi.org/10.1079/IVP2001257

Mok, M. C., Capelle, S. C., Kirchner, S. C., Mok, D. W. S., \& Armstrong, D. J. (1982). The effect of $\mathrm{N}$-phenyl-N-1,2,3-thiadiazol-5-ylurea (thiadiazorum) on cytikinin autonomy and the metabolism of ${ }^{34} \mathrm{C}-\mathrm{N} 6-\left(\Delta 2\right.$-isopentenyl) adenosine $\left({ }^{16} \mathrm{C}-6 \mathrm{Ado}\right)$ in callus cultures of Phaseolus lunatus $\mathrm{L}$. In Vitro, 18, 275.

Quainoo, A. K. (2006). Germplasm conservation of cocoa (Theobroma cacao L.) and virus elimination through tissue culture. PhD Thesis, School of Biological Sciences, University of Reading, UK. 192 pages.

Quainoo, A. K., A. C. Wetten., A. C., \& Allainguillaume, J. (2008). The effectiveness of somatic embryogenesis in eliminating the cocoa swollen shoot virus from infected cocoa trees. Journal of Virological Methods, 149(1), 91-96. http://dx.doi.org/10.1016/j.jviromet.2008.01.007

Raemakers, C. J. J., Jacobsen, E., \& Visser, R. G. F. (1995). Secondary somatic embryogenesis and applications in plant breeding. Euphytica, 81, 93-107. http://dx.doi.org/10.1007/BF00022463

Rehab, A. S., \& Zeinab, E. Z. (2011). Direct production of somatic embryos and plant egeneration using TDZ and CPPU of date palm (Phoenix dactyliffera L.). International Journal of Academic Research, Vol. 3 No. 2 Part III.

Shoemaker, R. C., L. A., Palmer, R. G., Oglesby, L., \& Ranch, J. P. (1991). Effect of 2, 4- dichlorophenoxyacetic acid concentration on somatic embryogenesis and heritable variation in soybean [Glycine max (L) merr.] In Vitro Cellular \& Developmental Biology - Plant, 27(2), 84-88. http://dx.doi.org/10.1007/BF02632133 
Xu, N., Coulter, K. M., \& Bewley, J. D. (1990). Abscisic acid and osmoticum prevent germination of developing alfalfa embryos but only osmoticum maintain the synthesis of developmental proteins. Planta, 182, 182-390. http://dx.doi.org/10.1007/BF02411389

Table 1. Effect of TDZ and 2, 4-D concentrations on the induction of somatic embryos of cocoa genotypes

\begin{tabular}{|c|c|}
\hline Treatment & Treatment combinations \\
\hline 1 & $1 \mathrm{mg} / 12,4-\mathrm{D}+1 \mu \mathrm{g} / 1 \mathrm{TDZ}$ \\
2 & $1 \mathrm{mg} / 12,4-\mathrm{D}+10 \mu \mathrm{g} / 1 \mathrm{TDZ}$ \\
3 & $4 \mathrm{mg} / 12,4-\mathrm{D}+1 \mu \mathrm{g} / 1 \mathrm{TDZ}$ \\
4 & $4 \mathrm{mg} / 12,4-\mathrm{D}+10 \mu \mathrm{g} / 1 \mathrm{TDZ}$ \\
5 (Control) & $2 \mathrm{mg} / 12,4-\mathrm{D}+5 \mu \mathrm{g} / 1 \mathrm{TDZ}$ \\
\hline
\end{tabular}

Table 2. Conversion frequency of somatic embryos into plantlets

\begin{tabular}{|c|c|c|c|}
\hline Genotypes & $\begin{array}{c}\text { Number of embryos } \\
\text { used }\end{array}$ & $\begin{array}{c}\text { Number of embryos converted } \\
\text { into plantlets }\end{array}$ & \% conversion \\
\hline AMAZ 3-2* & 7 & 2 & 28.57 \\
AMAZ 10-1* & 12 & 2 & 16.67 \\
COCA 2270-5* & 7 & 4 & 57.14 \\
GU 183 H* & 12 & 2 & 16.67 \\
AMAZ 3-2** & 46 & 7 & 15.22 \\
AMAZ 10-1** & 40 & 4 & 10 \\
COCA 2270-5** & 22 & 9 & 40.91 \\
GU 183 H** & 117 & 6 & 5.13 \\
\hline
\end{tabular}

Note: * represents primary somatic embryos $* *$ represents secondary somatic embryos

Table 3. The effect of TDZ and 2, 4-D concentrations on the induction of somatic embryos

\begin{tabular}{|c|c|c|}
\hline Treatment & COCA 3370-5 \% Embryogenesis & AMAZ 3-2 \% Embryogenesis \\
\hline $2 \mathrm{mg} / 12,4-\mathrm{D}+5 \mu \mathrm{g} / 1 \mathrm{TDZ}$ & $3.52 \mathrm{ab}$ & $7.62 \mathrm{a}$ \\
$1 \mathrm{mg} / 12,4-\mathrm{D}+1 \mu \mathrm{g} / 1 \mathrm{TDZ}$ & $4.19 \mathrm{a}$ & $5.10 \mathrm{~b}$ \\
$1 \mathrm{mg} / 12,4-\mathrm{D}+10 \mu \mathrm{g} / 1 \mathrm{TDZ}$ & $2.93 \mathrm{abc}$ & $1.54 \mathrm{c}$ \\
$4 \mathrm{mg} / 12,4-\mathrm{D}+1 \mu \mathrm{g} / 1 \mathrm{TDZ}$ & $1.81 \mathrm{c}$ & $4.46 \mathrm{~b}$ \\
$4 \mathrm{mg} / 12,4-\mathrm{D}+10 \mu \mathrm{g} / 1 \mathrm{TDZ}$ & $2.5 \mathrm{bc}$ & $1.50 \mathrm{c}$ \\
\hline LSD & 1.52 & 2.04 \\
\hline
\end{tabular}

Table 4. The effect of TDZ and 2,4-D treatment on the appearance of somatic embryos

\begin{tabular}{|c|c|c|c|c|c|c|}
\hline Treatment & $\begin{array}{c}\text { COCA } \\
3370-5\end{array}$ & $\begin{array}{c}\text { COCA } \\
3370-5\end{array}$ & $\begin{array}{c}\text { COCA } \\
3370-5\end{array}$ & $\begin{array}{c}\text { AMAZ } \\
3-2\end{array}$ & AMAZ 3-2 & AMAZ 3-2 \\
\cline { 2 - 7 } & $\begin{array}{c}\text { Number of } \\
\text { embryos }\end{array}$ & $\begin{array}{c}\text { Normal } \\
\text { embryos }(\%)\end{array}$ & $\begin{array}{c}\text { Abnormal } \\
\text { embryos }(\%)\end{array}$ & $\begin{array}{c}\text { Number } \\
\text { of } \\
\text { embryos }\end{array}$ & $\begin{array}{c}\text { Normal } \\
\text { embryos } \\
(\%)\end{array}$ & $\begin{array}{c}\text { Abnormal } \\
\text { embryos } \\
(\%)\end{array}$ \\
\hline $2 \mathrm{mg} / 12,4-\mathrm{D}+5 \mu \mathrm{g} / 1 \mathrm{TDZ}$ & 32 & 42.19 & 57.81 & 15 & 40 & 60 \\
$1 \mathrm{mg} / 12,4-\mathrm{D}+1 \mu \mathrm{g} / \mathrm{l} \mathrm{TDZ}$ & 24 & 45.83 & 54.17 & 18 & 47.22 & 52.78 \\
$1 \mathrm{mg} / 12,4-\mathrm{D}+10 \mu \mathrm{g} / 1 \mathrm{TDZ}$ & 7 & 42.86 & 57.14 & 12 & 45.83 & 54.17 \\
$4 \mathrm{mg} / 12,4-\mathrm{D}+1 \mu \mathrm{g} / \mathrm{l} \mathrm{TDZ}$ & 21 & 38.10 & 61.90 & 8 & 37.50 & 62.50 \\
$4 \mathrm{mg} / 12,4-\mathrm{D}+10 \mu \mathrm{g} / \mathrm{l} \mathrm{TDZ}$ & 8 & 37.50 & 62.50 & 12 & 33.33 & 66.67 \\
\hline
\end{tabular}




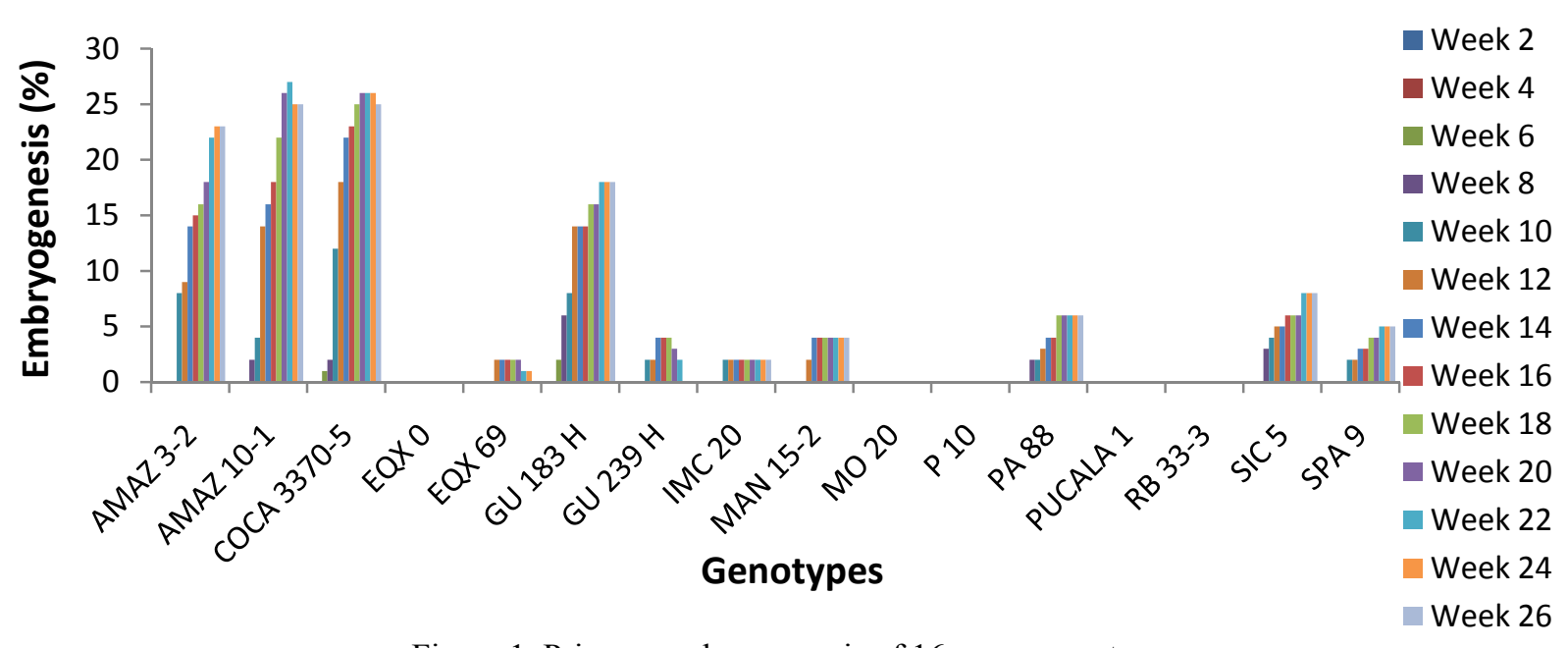

Figure 1. Primary embryogenesis of 16 cocoa genotypes

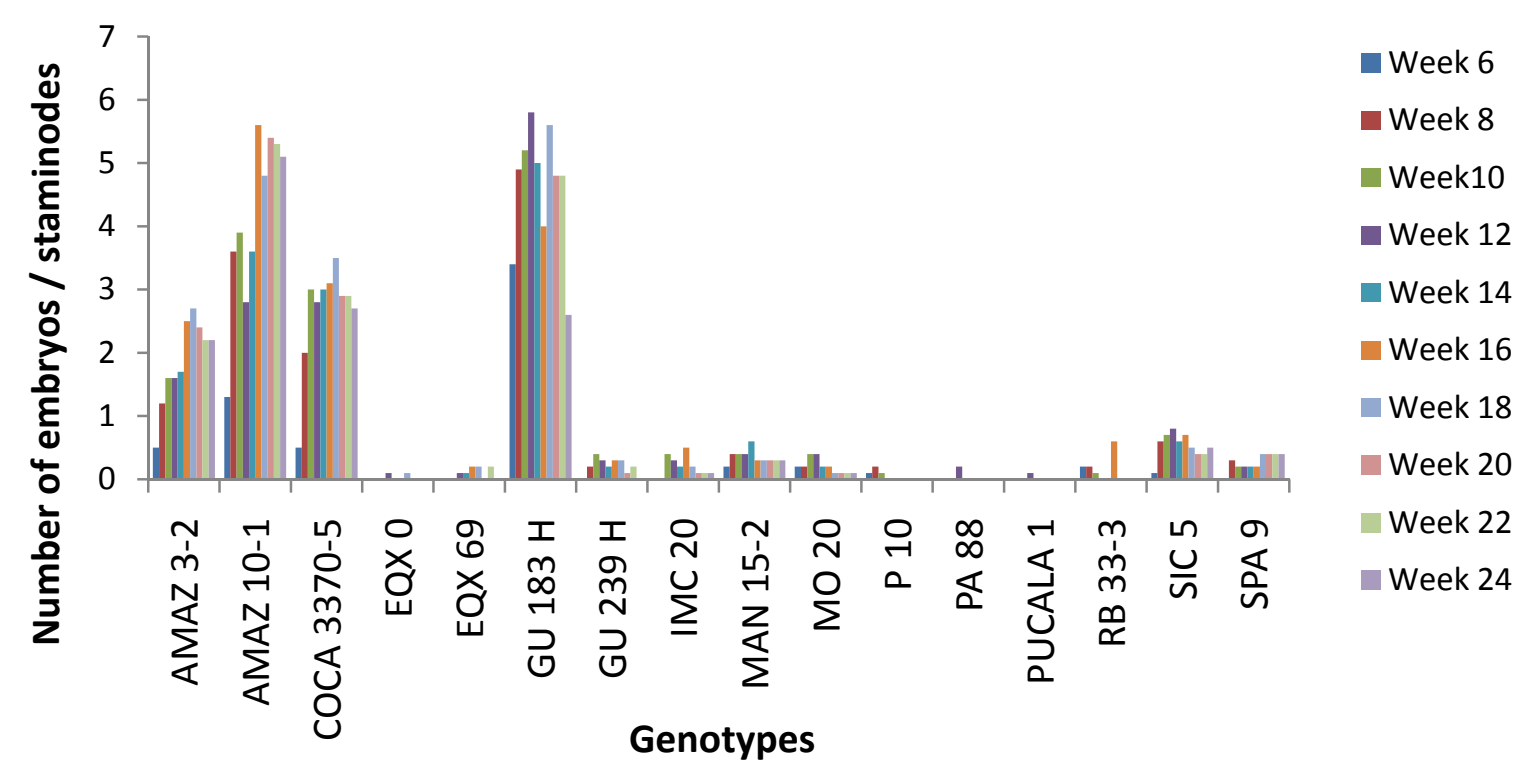

Figure 2. Number of somatic embryos per staminode generated by 16 cocoa genotypes 


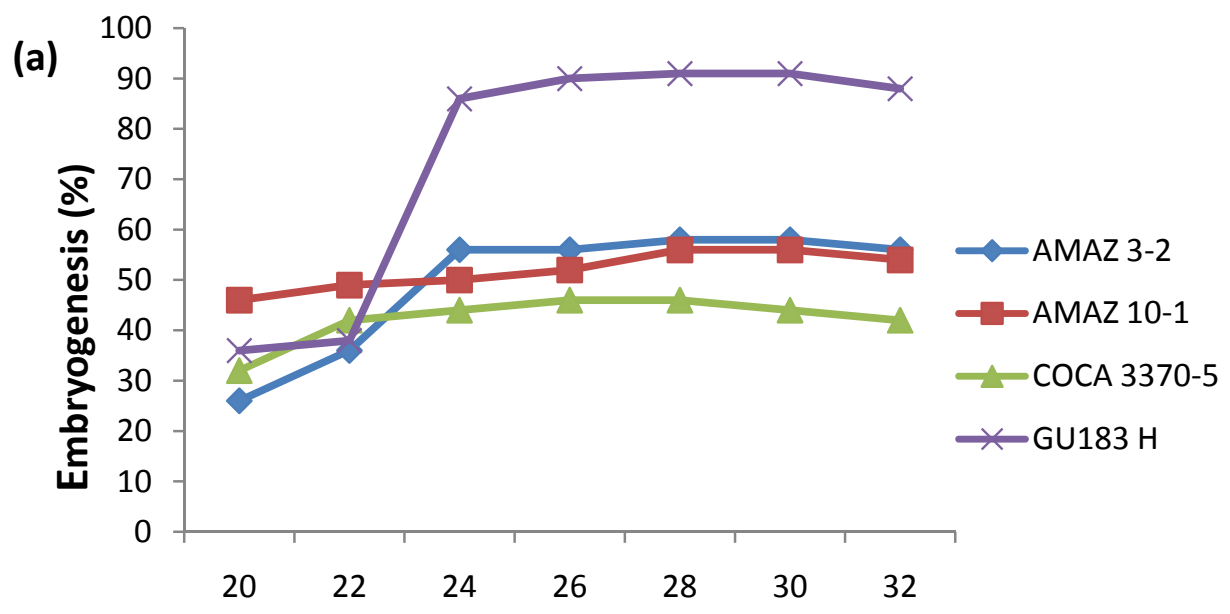

Weeks on embryo development medium

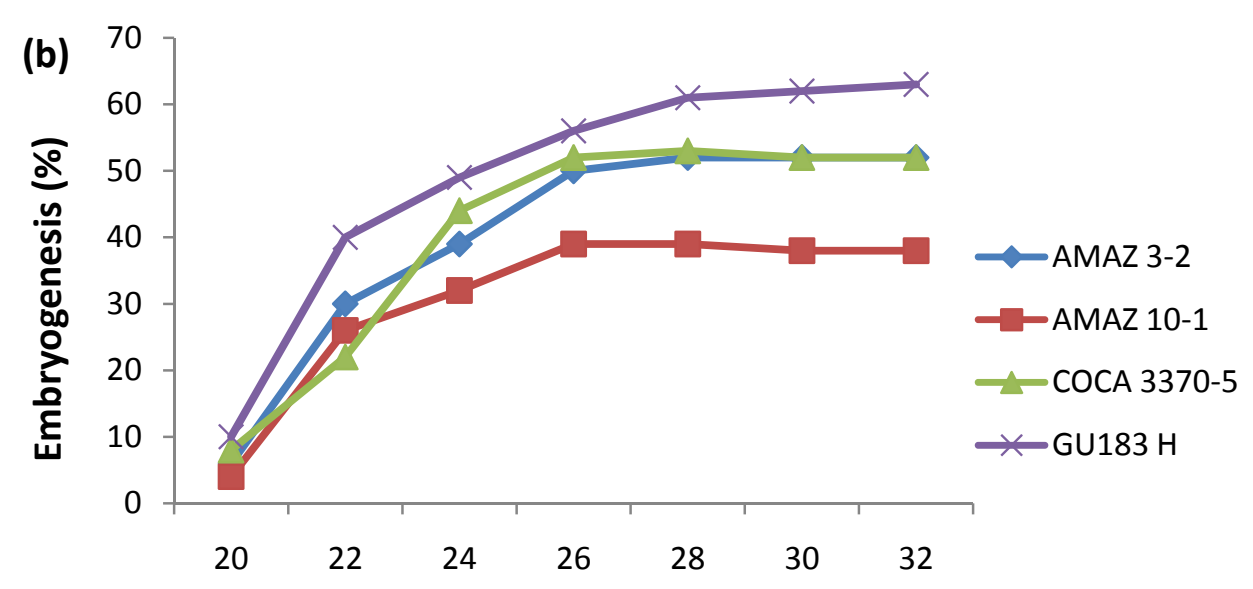

Weeks on embryo development medium

Figure 3. ( $a$ and b) Secondary embryogenesis of four cocoa geneotyps

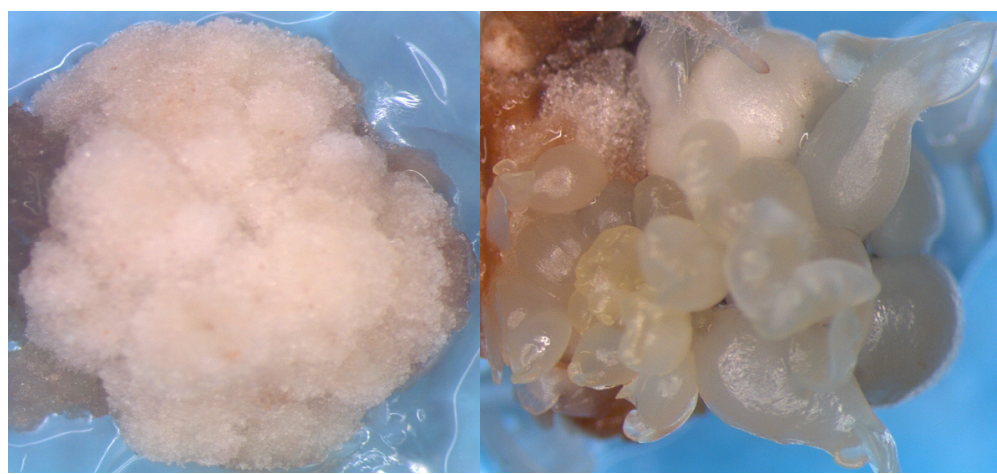

A

B

Figure 4. Somatic embryogenesis of cocoa
A. Callus tissues of staminode of cocoa
B. Somatic embryos of cocoa at different developmental stages 